\title{
Unsuspected coronary artery disease as cause of chronic atrioventricular block in middle age
}

\author{
WILLIAM GINKS, RICHARD SUTTON, HAROLD SIDDONS, \\ AUBREY LEATHAM
}

From the Department of Cardiology, St. George's Hospital, London

SUMMARY Attention has recently been drawn to the relatively poor prognosis of middle aged patients paced for chronic atrioventricular block when age-linked expectation of life is taken into account, and it has been suggested that this may be the result of underlying coronary artery disease, despite the absence of symptoms to suggest this. It was the purpose of this study to determine the incidence of unsuspected coronary artery disease in middle aged patients presenting with chronic atrioventricular block.

Studies were made on a consecutive series of 30 patients aged 45 to 65 (mean age 56 years) with chronic atrioventricular disease who had been referred for pacing. Patients presenting with acute myocardial infarction or angina or with sinuatrial disease without atrioventricular disease were excluded. Coronary arteriography disclosed the presence of severe coronary artery disease in 13 patients. Of the remaining 17 patients, four had congestive cardiomyopathy, two had hypertrophic cardiomyopathy, one had aortic stenosis, and in 10 patients the aetiology of the heart block was unknown.

Myocardial revascularisation was undertaken in six patients with paroxysmal atrioventricular block caused by coronary artery disease. Operation did not result in any sustained improvement in atrioventricular conduction.

Now that the technique of permanent pacing is well established in the management of chronic atrioventricular block, it seems likely that long term prognosis is dependent upon the aetiology of the heart block and in particular whether it is caused by idiopathic bundle-branch fibrosis, coronary artery disease, or cardiomyopathy. Attention has been drawn to the relatively poor prognosis of middle aged patients paced for chronic atrioventricular block when compared with older patients, if expectation of life, in relation to age, is taken into account, and it has been suggested that the poorer outlook in such patients is a result of the presence of underlying coronary artery disease. ${ }^{1}$

It was the purpose of this study to determine the incidence of occlusive coronary artery disease in middle aged patients presenting with evidence of chronic atrioventricular block and to assess the role of coronary vein bypass surgery in the treatment of such conduction disorders when paroxysmal.

Received for publication 9 April 1980

\section{Patients and methods}

Since 1976 we have investigated, by cardiac catheterisation and coronary arteriography, all patients aged 65 years or less who were referred for pacing because of chronic atrioventricular conducting tissue disease.

Thirty patients, eight women and 22 men, with an average age of 56 years, fulfilled these criteria. Patients with rhythm disturbances after acute myocardial infarction and patients with sinuatrial disease without atrioventricular disease were excluded.

Electrocardiographic monitoring at the bedside was undertaken in all cases and a portable 24 hour electrocardiogram was also obtained with an Avionics composite electrocardioscanner. In 12 patients, intracardiac electrocardiographic studies were performed in order to determine the mechanism of heart block. ${ }^{2}$ Cardiac catheterisation was undertaken in all patients and the coronary artery 
anatomy was defined using the technique described by Sones and Shirey, ${ }^{3}$ severe disease in the lumen of the major coronary arteries being defined as 70 to 100 per cent stenosis.

\section{Results}

The clinical data of the 30 patients are shown in Table 1 . The majority of patients presented with dizziness or syncope. There were three patients in whom the primary complaint was dyspnoea. Two patients were free of symptoms. Five patients admitted to mild chest discomfort which was insufficiently severe to report to their referring physician. In one of them a history of myocardial infarction 11 years before was elicited.

Table 1 Clinical data on patients with chronic atrioventricular block

\begin{tabular}{lc}
\hline No. of patients & 30 \\
Age & 56 (range 45 to 65 years) \\
Sex & 22 \\
$\quad$ Male & 8 \\
Female & \\
Presenting complaint & 19 \\
Syncope & 6 \\
Dizziness & 3 \\
Dyspnoea & 2 \\
No symptoms & \\
\hline
\end{tabular}

Of the 30 patients, atrioventricular block was paroxysmal in 17 and permanent in 13 . The electrocardiographic findings are shown in Table 2. Three of the 17 patients with intermittent atrioventricular block had QRS complexes of normal duration, and conduction delay was considered to be proximal to the bundle of His. The remaining 14 patients with paroxysmal atrioventricular block had electrocardiographic evidence of bifascicular block; atrioventricular block was therefore considered to be the result of impaired conduction distal to the bundle of His, and this was confirmed in seven of the patients who underwent intracardiac electrocardiography.

Table 2 Electrocardiographic findings in 30 patients with atrioventricular block

\begin{tabular}{lcc}
\hline Intermittent & & 17 \\
QRS < 0.12 s & 3 & \\
RBBB + LAH & 6 & \\
LBBB & 7 & \\
RBBB alternating LBBB & 1 & \\
Permanent & 3 & 13 \\
QRS < $0.12 \mathrm{~s}$ & 3 & \\
QRS > $0.12 \mathrm{~s}$ & 10 & \\
\hline
\end{tabular}

LAH, left anterior hemiblock; RBBB, right bundle-branch block; LBBB, left bundle-branch block.

Thirteen patients had permanent atrioventricular block. Three of these had a QRS complex of normal duration, and conduction delay was considered to be the result of block at atrioventricular or intraHisian level. The remaining 10 patients had a QRS duration of greater than $0 \cdot 12 \mathrm{~s}$ and were considered to have infraHisian conduction delay.

Table 3 Angiographic findings in 30 patients with atrioventricular block

\begin{tabular}{lr}
\hline Normal & 10 \\
Severe coronary artery disease & 13 \\
Congestive cardiomyopathy & 4 \\
Hypertrophic cardiomyopathy & 2 \\
Aortic stenosis & 1 \\
\hline
\end{tabular}

The results of further investigations in the 30 patients with atrioventricular block are shown in Table 3. Thirteen patients had severe coronary artery disease. The remaining 17 patients had either insignificant or no coronary disease; two of these 17 had hypertrophic cardiomyopathy, four patients had congestive cardiomyopathy, one had severe aortic stenosis, and 10 patients had no evidence of additional heart disease. Those patients without evidence of coronary artery disease as a cause of atrioventricular block were managed by permanent endocardial pacing.

Table 4 Distribution of coronary artery disease in 13 patients with atrioventricular block and related His bundle findings

\begin{tabular}{llll}
\hline $\begin{array}{l}\text { Distribution of } \\
\text { coronary artery disease }\end{array}$ & $\begin{array}{l}\text { No. of } \\
\text { patients }\end{array}$ & $\begin{array}{l}\text { AV nodal } \\
\text { block }\end{array}$ & $\begin{array}{l}\text { InfraHisian } \\
\text { block }\end{array}$ \\
$\begin{array}{l}\text { Right, LAD + diagonal, } \\
\quad \text { circumflex + marginal arteries }\end{array}$ & 4 & 1 & 3 \\
$\begin{array}{l}\text { Left main stem, LAD + diagonal, } \\
\text { circumflex arteries }\end{array}$ & 1 & - & 1 \\
$\begin{array}{l}\text { Right, LAD + diagonal arteries } \\
\text { Right coronary + circumflex }\end{array}$ & 3 & - & 3 \\
$\quad$ arteries & 1 & - & 1 \\
$\begin{array}{l}\text { LAD + diagonal arteries } \\
\text { Right coronary artery only }\end{array}$ & 2 & - & 2 \\
\hline
\end{tabular}

Of the 13 patients with coronary artery disease and atrioventricular block, left ventricular angiography was considered normal in five patients and abnormal in eight. The distribution of the coronary artery disease in these patients is shown in Table 4, and these results show that three of the 13 patients with coronary artery disease and atrioventricular block had delay proximal to the bundle of His and severe stenosis or occlusion of a dominant right coronary artery; 10 had conduction delay distal to the bundle of His associated with left anterior descending coronary artery stenosis, proximal to or involving the origin of the first septal perforating artery in eight cases. There were nine patients with coronary artery disease and paroxysmal atrioventricular block and the other four patients had permanent atrioventricular block. 
Myocardial revascularisation by coronary vein bypass grafting was undertaken in six patients with paroxysmal atrioventricular block caused by coronary artery disease. Five patients before operation had had recurring paroxysmal atrioventricular block, shown by intracardiac electrocardiography to be infraHisian in site. After operation in each case there was a temporary return to sinus rhythm during the first few postoperative days but this was followed by a recurrence of paroxysmal atrioventricular block. These patients had demand endocardial pacemakers inserted before hospital discharge.

The remaining patient had had infrequent episodes of atrioventricular block and the effect of operation was difficult to assess. This patient, however, has remained symptom free in the 12 months since operation without the need for permanent pacing.

\section{Discussion}

The aetiology of chronic atrioventricular block is frequently difficult to determine in the living patient. ${ }^{4}$ Even a history of cardiac pain on effort may not indicate coronary disease since it may be secondary to slow heart rates or to cardiomyopathy. Coronary disease was undoubtedly implicated too often in the past, ${ }^{5-9}$ and factors exaggerating its importance were the not uncommon precipitation of acute heart block by infarction and electrocardiographic evidence of changing $T$ waves which may not be recognised as simply occurring secondary to pacing. ${ }^{10}$ In this series the electrocardiogram was of no value in predicting the presence of underlying coronary disease. It was of interest that the majority of patients had a wide QRS complex and this observation compares closely with our clinicopathological findings in a series of 134 patients with chronic complete heart block of whom 111 had a QRS duration of greater than $0 \cdot 12 \mathrm{~s}$.

The incidence of coronary artery disease as a cause of chronic heart block in the elderly was studied at necropsy by Davies. ${ }^{11}$ In a series of 100 patients (mean age 70 years) he found that only 15 per cent of the patients had coronary artery disease of sufficient severity to account for the heart block. Thus, isolated disease of the conduction tissue was the most common cause of chronic atrioventricular block and this explains the relatively normal expectation of life once paced. ${ }^{12}$ Younger patients do not fare as well when age-linked expectation of life is taken into account ${ }^{1}$ and the finding of severe coronary disease in 13 of the present series of 30 patients probably accounts for this observation. The incidence of coronary artery disease in a con- trolled normal population of similar age is unknown. Indirect evidence taken from patients undergoing isolated aortic valve replacement for a congenitally bicuspid valve or mitral valve replacement for rheumatic mitral valve disease suggests the presence of additional unrelated coronary artery disease in approximately 20 per cent of patients. ${ }^{13}$ (and unpublished data) Thus, the higher incidence of coronary artery disease in those patients with chronic atrioventricular block makes it the likely cause of the conduction disturbance rather than an associated finding.

An understanding of the pathological processes involved in the production of atrioventricular block by coronary artery disease can only be based on knowledge of the blood supply to the conduction system. The most elegant demonstration of this aspect is the work of James and Burch ${ }^{14}$ using a vinylite injection technique. In 43 human hearts examined, the coronary artery which crossed the posterior crux of the heart (right $83 \%$, left $7 \%$, and both $10 \%$ ) supplied the atrioventricular node, main bundle, and the origins of the bundle-branches. The bulk of the interventricular system was supplied by long penetrating branches derived from the anterior descending coronary artery. The anatomical findings of James and Burch have been confirmed in a postmortem angiographic study of 192 human hearts. ${ }^{15}$ On a theoretical basis in man, right coronary artery occlusion would cause nodal ischaemia and conduction delay proximal to the bundle of His; left anterior descending occlusion would cause bundlebranch ischaemia and delayed conduction distal to the bundle of His.

In our study, it was therefore of considerable interest to find a direct relation between the anatomical distribution of the coronary disease and the level of atrioventricular block, a correlation which appears to hold more closely for left anterior descending disease than for right coronary artery disease, though an isolated right coronary stenosis was an uncommon finding.

When heart block is paroxysmal in patients with obstructive coronary artery disease it is tempting to consider coronary vein bypass surgery in their management but so far the results have been disappointing. The early return to sinus rhythm observed in all patients during the perioperative period was presumably related to increased sympathomimetic drive. Coronary artery bypass grafting conceivably improved conduction in the one patient with conduction delay proximal to the bundle of His. The lack of success in the remaining cases probably reflects irreversibility of conducting tissue damage.

In conclusion, this study indicates that there is a high incidence of severe coronary artery disease in 
those patients less than 65 years of age with chronic atrioventricular block (13 of 30 cases). In addition, there was a close relation between the level of the heart block and the distribution of the coronary artery disease. Lastly, coronary bypass surgery proved to be ineffective in improving distal atrioventricular conduction in those patients with paroxysmal atrioventricular block which was considered to be a result of occlusive coronary artery disease.

\section{References}

1 Ginks W, Leatham A, Siddons H. Prognosis of patients paced for chronic atrioventricular block. Br Heart f 1979; 41 : 633-6.

2 Scherlag BJ, Lau SH, Helfont RH, Berkowitz WD, Stein E, Damato AN. Catheter technique for recording His bundle activity in man. Circulation 1969; 39: 13-8.

3 Sones FM Jr, Shirey EK. Cine coronary arteriography. Mod Concepts Cardiovasc Dis 1962; 31: 735-8.

4 Harris A, Davies $M$, Redwood D, Leatham A, Siddons H. Aetiology of chronic heart block. A clinico-pathological correlation in 65 cases. $\mathrm{Br}$ Heart $\mathcal{f}$ 1969; 31: 206-18.

5 Kay HB. Ventricular complexes in heart block. Br Heart f 1948; 10: 177-87.

6 Penton GB, Miller H, Levine SA. Some clinical features of complete heart block. Circulation 1956; 13: 801-24.

7 Wright JC, Hejtmancik MR, Herrmann GR, Shields AH. A clinical study of complete heart block. Am Heart f 1956; 52: 369-87.

8 Rowe JC, White PD. Complete heart block: a follow-up study. Ann Intern Med 1958; 49: 260-70.

9 Friedberg CK, Donoso E, Stein WG. Non-surgical acquired heart block. Ann NY Acad Sci 1964; III: 835-47.

10 Chatterjee K, Harris A, Davies G, Leatham A. Electrocardiographic changes subsequent to artificial ventricular depolarisation. $\mathrm{Br}$ Heart $\mathcal{f}$ 1969; 31: 770-9.

11 Davies MJ. Pathology of the conducting tissue of the heart. London: Butterworths, 1971.

12 Siddons H. Deaths in long-term paced patients. Br Heart f 1974; 36: 1201-9.

13 Swanton RH, Brooksby IAB, Jenkins BS, et al. Determinants of angina in aortic stenosis and the importance of coronary arteriography. $\mathrm{Br}$ Heart $\mathcal{f}$ 1977; 39: 1347-52.

14 James TN, Burch GE. Blood supply of the human inter-ventricular septum. Circulation 1958; 17: 391-6.

15 Romhilt DW, Hackel DB, Estes EH Jr. Origin of blood supply to sinoauricular and atrioventricular node. Am Heart f 1968; 75: 279-80.

Requests for reprints to Dr William Ginks, Department of Cardiology, St George's Hospital, Blackshaw Road, London SW17 0QT. 